\title{
DOCUMENTOS
}

\section{El discurso sobre la música para cine en Colombia: una aproximación bibliográfica ${ }^{1}$}

\author{
The Discourse about Film Music in Colombia: \\ a Bibliographical Approach
}

\author{
por \\ Marco Alunno \\ Departamento de Música, Universidad EAFIT, Medellín, Colombia \\ malunno@eafit.edu.co \\ www.marcoalunno.com
}

La motivación para investigar un patrimonio sumergido como es la literatura acerca de la música para el cine en Colombia, surge del desconocimiento que los investigadores de Europa y Estados Unidos -quienes históricamente han tratado la música para el cine- han demostrado acerca de la literatura relativa a la música para el cine en América Latina. Desde una época temprana, las tentativas de hablar discursivamente acerca de la música para el cine afloran en Colombia en artículos publicados en revistas dedicadas al cine, la música, el arte y la cultura en general. El enfoque de los artículos es frecuentemente divulgativo, pero no están ausentes los escritos más especializados. El presente trabajo es el resultado de una investigación de archivo, y pretende brindar una imagen de la bibliografía respecto del tema existente en Colombia, como punto de partida para estudios ulteriores.

Palabras clave: Colombia, música, cine, revistas, bibliografías.

The motivation to explore the hidden heritage of literature on film music in Colombia, originated from the absence of literature on Latin American film music written by scholars from Europe and the United States, who have traditionally dealt with film music. Since an early period attempts to speak discursively about film music in Colombia appear in articles published in magazines and journals dedicated to cinema, music, art and cultural topics in general. These writings are often addressed to general audiences. Nevertheless there are also a few writings intended for specialized readers. The present article is based on archival research and presents a snapshot of the existing literature about film music in Colombia as a starting point for future studies.

Keywords: Colombia, film music, cinema, reviews, bibliography.

${ }^{1}$ El presente trabajo es el resultado de la investigación homónima realizada con financiamiento interno de la Universidad EAFIT (Medellín, Colombia) en 2012. Los datos reportados tienen como fecha de corte octubre del mismo año. Parte de este artículo fue objeto de una comunicación en el VII Simposio Internacional "La creación musical en la banda sonora", Universidad de Oviedo, 13-14 de diciembre de 2012. 


\section{POR QUÉ ESTA INVESTIGACIÓN ES NECESARIA}

La música para cine nace con el cine mismo; por tanto, es desde el tiempo del nacimiento del cine que ocasionalmente se habla de ella. Si hubo un incremento en la producción literaria respecto del tema en los últimos cuarenta años es porque esta literatura ha logrado diferenciarse. Por una parte, desde la visión musicológica y teórica -la más reciente-. Por la otra, desde la perspectiva del periodismo y de la crónica -la más antigua, que se distingue de la primera por brindar puntos de vista no respaldados por una metodología científica de investigación y que, sin embargo, encuentra espacios no solo en los periódicos y revistas de interés general, sino, a veces, en publicaciones temáticas y especializadas. La separación entre las dos producciones literarias se genera en el momento en que aparece clara la necesidad de convertir el discurso alrededor de la música para cine $-\mathrm{y}$, por extensión, de la música aplicada- en un tema digno de pertenecer a las disciplinas musicológicas ${ }^{2}$.

Como se puede notar, hay una relación de precedencia temporal entre la literatura de la música para cine y la música para cine como estudio musicológico, lo que parece indicar que la segunda surgió de un interés que ya había demostrado la primera. Lógicamente, todo hace pensar que esta última puede tener escondidas algunas semillas representativas de lo que serán sus frutos futuros. Por esta razón, es necesario estudiarla con método y dedicación. Si en alguna circunstancia no se ha hecho todavía, es porque en los países donde la música para cine ha tenido que luchar para establecerse como disciplina de estudio, la distancia entre ella y la literatura de carácter periodístico ha sido la consecuencia de un proceso de autoafirmación ${ }^{3}$. En todo caso, es tautológico que la existencia de un pensamiento musicológico es conditio sine qua non para que la música, más allá de ser un punto de atención superficial y puramente emotivo, pueda aspirar a ser objeto de estudio. Sin embargo, ¿qué deberíamos hacer con todo lo que se dijo acerca de la música para cine en países en los que la producción literaria se clasifica, casi por completo, en una franja de tipo divulgativo? ¿Deberíamos ignorarlo? Hablamos aquí de países en los que la musicología es todavía una disciplina joven y, como tal, tiene prioridades específicas que generalmente no incluyen la música para cine sino la preservación de la memoria musical de la nación y de las tradiciones autóctonas.

Esto no significa que haya que esperar tiempos mejores para que se pueda enfrentar el discurso de la música para cine desde un enfoque musicológico. Hasta la fecha, los estudios de música aplicada han sido principalmente una prerrogativa de los países europeos y norteamericanos ${ }^{4}$, estos, si no niegan que pueda existir una producción literaria sobre el tema en los países de América Latina, en efecto la ignoran. Una razón reside seguramente en el hecho de que, como ya pasó en Europa y Norteamérica, esta producción no está donde uno más esperaría encontrarla, o sea, en las revistas de música. En realidad, la naturaleza interdisciplinaria de la música aplicada hizo que los primeros en ocuparse de ella fueran estudiosos del cine o de los fenómenos culturales. La otra razón es independiente de factores interdisciplinarios o geográficos, porque se halla ligada a la inestabilidad y escasa

2 Quizás uno de los primeros trabajos de este tipo sea Estetyka muzyki filmowej de Zofia Lissa (publicado en Cracovia en 1964) que la editorial Henschel volvió a imprimir el año siguiente en Berlín en traducción alemana con el título Ästhetik der Filmmusik.

3 Es por ejemplo el caso de Italia, donde los estudios académicos, influenciados por la estética crociana, han mantenido a los márgenes durante décadas toda actividad humana relacionada con lo artesanal y lo funcional, cuyos ejemplos son, respectivamente, las llamadas "artes menores" y la música para cine (Miceli 1990a: 201-222 y 1990b: 7-13).

4 Aquí y más adelante nos referimos mediante la voz Norteamérica a Canadá y Estados Unidos solamente. 
difusión de la producción cinematográfica de muchos países latinoamericanos, de lo que hablaremos en mayor detalle más adelante. No son ciertamente estos los únicos motivos que explican la invisibilidad de un continente a los ojos de otro continente ${ }^{5}$, pero sirven de directiva para el discurso que sigue. No por acaso, este es el contexto en el que se inscribe Colombia. Por un lado, una escuela musicológica relativamente joven, cuyos esfuerzos están, por el momento, enfocados en el trabajo de archivo, recuperación e interpretación de un patrimonio musical olvidado y en deterioro ${ }^{6}$. Por el otro, una industria cinematográfica que, solo en los últimos diez años, ha mostrado tener intenciones serias de afirmarse como negocio sólido y económicamente rentable?

Reconocemos que es difícil generalizar ${ }^{8}$ pero esta podría ser, razonablemente, la situación en la que se encuentran la mayoría de los países latinoamericanos, excepción hecha, obviamente, de México, Brasil y Argentina que, por lo menos cinematográficamente hablando, gozan de una tradición rica e influyente. Aquí se explica por qué el título del presente artículo indica como objeto de estudio una realidad definida -la colombiana-, sin perder la esperanza de proyectarse un día en una dimensión más amplia -la latinoamericana-.

Obviamente, el formato de un artículo no permite una mayor profundización en las materias que es necesario conocer para abordar el objeto de la música para cine en Colombia. Sin duda, el conocimiento previo de, por lo menos, la historia del cine colombiano ${ }^{9}$ y la historia de la música en Colombia (por ej. Perdomo Escobar 1945) ofrecerán al lector más informaciones acerca de autores y argumentos de cuanto pueda hacerlo una bibliografía, aunque sea parcialmente comentada, como la que presentamos en este trabajo. Es exactamente en función de la especificidad del tema por lo que consideramos oportuno brindar al lector, primero que todo, unos lineamientos generales de la historia del cine colombiano.

De allí que el sujeto de este artículo volverá al tema musical para definir cuáles han sido los límites autoimpuestos al proceso investigativo y sus alcances. Esto con el fin de introducir el siguiente apartado respecto de la apreciación de la música para cine en páginas de revistas, programas de radio y tesis de estudiantes universitarios en Colombia.

5 Sin duda, no hay motivos de carácter lingüístico, como es fácil imaginar que ocurra con una, por nosotros desconocida, producción literaria en países asiáticos.

6 Si bien los primeros estudios histórico-musicales importantes aparecieron entre 1930 y 1940 (Perdomo Escobar 1945; Igualada 1938: 638-861), la musicología en sentido moderno, aunque enfocada principalmente en lo etnomusicológico, quizás haya nacido con Andrés Pardo Tovar (1966: 22-36; citado en Bermúdez 2006: 7-83). Respecto de la música para cine, algunos de los más reconocidos musicólogos del momento -Egberto Bermúdez, Jaime Cortés Polanía, Ellie Anne Duque Hyman y Fernando Gil Araque, en comunicación personal con el autor-, concuerdan en reconocer que, si no se ha hecho mucho en este campo, se debe en parte a la juventud de la musicología colombiana.

7 La Ley 814 de 2003, o Ley del Cine, presenta la importante novedad, respecto de otras leyes o empresas del pasado (por ejemplo la Ley Novena de 1942 y la Compañía de Fomento Cinematográfico en 1978), de brindar beneficios tributarios a los que inviertan en las producciones cinematográficas (Cap. III, art. 16 y 17). Permite a los directores "vender" sus proyectos en la bolsa de valores como si se tratara de una emisión de acciones. Sin embargo, en el 2009 Juana Suárez hacía notar que "hasta la fecha no se cuenta con ningún proyecto cinematográfico colombiano que ofrezca las condiciones de seguridad y control de riesgo que justifique una titularización ante la Superintendencia Financiera" (Suárez 2009: 212). Los decretos de la ley 814 se pueden descargar en la siguiente dirección: http:// www.mincultura.gov.co/?idcategoria=23666 (consulta: 3 de octubre de 2012).

8 No realizamos ninguna investigación por fuera de Colombia, así que lo que se señala acerca de América Latina es una mera hipótesis.

9 Por ejemplo los textos de Martínez Pardo (1978) -para el cine colombiano hasta 1978-y Juana Suárez (2009) -para una visión más contemporánea, no organizada en forma de relato histórico, sino que a partir de ensayos críticos-. 
Sin embargo, por razones de espacio y relevancia de las fuentes, en el capítulo sucesivo concentraremos nuestra atención solo en dos documentos que efectivamente merecen ser presentados al público, mientras que la bibliografía completa, por ser con frecuencia de bajo nivel histórico-crítico, se encontrará clasificada temáticamente en el apéndice.

Queremos finalmente enfatizar que nuestro enfoque es solo uno de los posibles puntos de partida para el estudio de la música para cine en el continente latinoamericano. De hecho, redactar y comentar una bibliografía no es para nosotros un fin sino un medio para empezar un discurso nuevo, científicamente calificado y musicológicamente informado. El análisis de determinadas películas, la reconstrucción de un período histórico o el examen de la filmografía de un director en particular constituyen otras perspectivas igualmente perseguibles. Es así como, en cierto sentido, nuestra investigación se pone como meta algo que las corrientes musicológicas colombianas, como se ha constatado precedentemente, ya están haciendo desde hace algún tiempo en otros campos: catalogar y preservar materiales, compararlos y promover un acercamiento crítico. Esperemos que nuestro comienzo sea bienvenido y estimule operaciones análogas en otros países latinoamericanos.

\section{BREVE HISTORIA DEL CINE COLOMBIANO}

Así como ocurrió en muchos países del mundo, la penetración del cinematógrafo Lumière en Colombia fue muy temprana. Queda registro de que ya en 1897, solo dos años después de la invención de los hermanos franceses, se dieron en el puerto de Colón (actual Panamá y, en ese entonces, territorio colombiano) las primeras proyecciones cinematográficas por mano del francés Gabriel Veyre y de la Compañía Universal de Variedades del empresario Balabrega. Mucho de lo que venía de Europa entraba a Colombia a través del puerto de Colón. Otras regiones urbanas del país, como Medellín, Cali y Bogotá, orográficamente eran de difícil acceso. De hecho Veyre, inicialmente muy animado en llevar el cine a la hodierna capital colombiana, desistió a mitad de camino y volvió a Francia.

Después de un comienzo prometedor, el cine y otros tipos de diversiones se vieron, sin embargo, interrumpidos pronto por la Guerra de los Mil Días (1899-1902), la misma en la que Colombia perdería, adicionalmente, el territorio panameño. A pesar de todo, el espectáculo del cine se reanudó inmediatamente en 1903, año en el que los hermanos italianos Di Domenico llegaron al puerto de Colón para, en 1909, mudarse definitivamente a Bogotá. Ellos, los Acevedo y el también italiano Florio Manco (en Barranquilla), fueron los pioneros del cine colombiano. Además de mostrar películas de procedencia europea (principalmente italiana y francesa) todos se dedicaron a la producción de películas originales, siendo el género documental, de crónica y de reconstrucción de eventos históricos en formato de cortometraje el preferido, sobre todo por los Acevedo. A los Di Domenico se deben además el nacimiento de las primeras dos revistas colombianas dedicadas al cine (Olympia, 1915 y Películas, 1916), así como la primera sociedad productora -la Sicla-, y el impulso a la construcción del teatro Olympia en Bogotá, el primer espacio cubierto de la capital consagrado a espectáculos masivos.

Lo siguieron muchos otros en la segunda década del siglo y, con ellos, también muchas más películas de producción colombiana. Son de estos años los primeros éxitos de ficción cinematográfica nacional: María (dir. Alfredo del Diestro y Máximo Calvo, 1922), Aura o las violetas (dir. Pedro Moreno Garzón, 1924), La tragedia del silencio (1924) -a la que pertenece una de las dos fuentes de interés presentadas en el apartado 5-, y Bajo el cielo antioqueño (1925), ambas dirigidas por el padre de los Acevedo, Arturo Acevedo Vallarino. Otras doce películas mudas completan la producción cinematográfica colombiana en la década de los veinte, antes de que el cine sonoro se impusiera rápidamente en el nivel internacional y 
el mercado interno viera las importaciones de películas europeas y la productividad local remplazadas por la entrada consistente del cine norteamericano.

La baja en la producción nacional se debió también a la dificultad encontrada por los exhibidores, de hacer frente a los costos de implementación de los sistemas Vitaphone y Movietone. Con el cine sonoro en pleno auge, toda la década de los treintas está marcada por el perfeccionamiento de un aparato de fabricación colombiana: el "cronofotófono" del ingeniero alemán-colombiano Carlos Schroeder. A pesar de que la invención finalmente no fue tan exitosa como pareció en un primer momento, llegó igualmente a dejar rastro de sí en el trabajo conjunto de Schroeder y los Acevedo (ver el apartado 5). Sin embargo, para asistir al primer largometraje de ficción sonoro y parlante de la historia del cine colombiano (Flores del valle, dirigido por el español Máximo Calvo, ya autor de María en 1922) hubo que esperar hasta 1941. Para ese entonces, las cinematografías mexicana y argentina, que podían capitalizar por la facilidad de exportación debida al idioma, habían recortado una buena tajada del mercado a los distribuidores norteamericanos que, como reacción, empezaron la producción de películas dobladas al español.

Los años cuarenta no se caracterizan seguramente por la producción de largometrajes de ficción que fue bien escasa (con el de Calvo, vale mencionar Allá en el trapiche y Bambucos y corazones, producidos por la Ducrane Films de los hermanos Duperly en 1943 y 1945, respectivamente) sino, más bien, por la promulgación de la "ley novena" de cine en 1942, la primera en su género en el país. El reconocimiento jurídico del fomento al cine colombiano proporcionaba un marco legal indispensable para poder fundar las bases de una industria cinematográfica nacional. Esto, sin embargo, no podía compensar algunas fallas técnico-estructurales en el cine de ficción nacional; en particular, la ausencia de un sistema productivo organizado y rentable y la falta de equipos y de personal capacitado en hacer películas sonoras. A esta última razón se pueden atribuir, además, las tendencias costumbristas y paisajistas del cine colombiano de ficción que, por medio de canciones y vistas bonitas, lograba tanto evitar las dificultades de grabar con claridad los diálogos como amortiguar la torpeza de los actores. A pesar de todo, la década de 1950 produjo los primeros cineclubes (como el Cine Club de Colombia), los primeros ejemplos de periodismo especializado (Hernando Salcedo Silva, Alberto Aguirre y Orlando Mora), y las primeras películas que se distanciaron del folclorismo y de la imitación de modelos extranjeros ( $L a$ langosta azul, dir. Luis Vicens Estrada, 1954; La gran obsesión, dir. Gillermo Ribón, 1955, y El milagro de la sal, dir. Luis Moya, 1958).

El carácter amateur del cine colombiano empezó a cambiar a mediados de los años sesenta, cuando regresaron al país algunos cineastas que se habían formado en el exterior. Salcedo Silva (1981) denominó a este grupo "Los Maestros", pero, en realidad, nunca formaron escuela aunque sí establecieron las bases para el desarrollo de un cine profesional colombiano. Algunos regresaban de París (Francisco Norden, Marta Rodríguez), otros de Roma (Guillermo Angulo, Roberto Triana) para dar vida a un cine verdaderamente colombiano, no importaba si documental (Gabriela Samper, Francisco Norden), de denuncia (Jorge Silva, Marta Rodríguez), político (Julio Luzardo, Francisco Norden) o de comedia (Lizardo Díaz). Sin embargo, la agresividad mercantil de los distribuidores norteamericanos radicados en el país y una ley demasiado débil en imponer cuotas de mercado justas, mantuvieron la ya escasa producción colombiana en una posición constantemente precaria que solo las coproducciones internacionales y la inusual presencia de muchos cineastas extranjeros en el país durante toda la década, lograron vigorizar.

En el clima altamente politizado que el cine de los años setenta heredó de la década precedente, terminó la ausencia crónica de apoyo estatal al cine nacional. Mediante un decreto de 1971 se establecieron las cuotas de pantalla por destinarse a la producción local, se impuso la presencia de un corto colombiano antes de cualquier proyección y se 
aplicó un sobreprecio en las boletas para que los ingresos se repartieran entre productor y distribuidor. La creación de la Compañía de Fomento Cinematográfico (Focine) en 1978 y la así llamada "época del sobreprecio" dejaron como legado más de ochocientos cortometrajes, "con una calidad dispar y una muy animada generación de cineastas" (FPFC, 2009?: 66). Sin embargo, la producción de largometrajes no logra afirmarse y queda en las manos de iniciativas privadas, al margen de la política del sobreprecio. Es este el caso de directores activos, tanto en la comedia popular (los éxitos taquilleros de Gustavo Nieto Roa con Esposos en vacaciones, 1977 y Colombia Connection, 1978) o en el género de fantasía y horror (el terror criollo de bajo presupuesto de Jairo Pinilla en Funeral siniestro, 1978 y Área maldita, 1979) como en el cine políticamente comprometido (los ya mencionados Marta Rodríguez y Jorge Silva con Nuestra voz de tierra, memoria y futuro, 1982).

Un decreto gubernamental del 1992 puso la palabra fin a Focine, compañía que, en quince años de gestión, no llegó a cumplir con su misión de establecer una sólida industria cinematográfica en Colombia. La falta de una correcta planificación conceptual y política del fomento cinematográfico dejó muchas pérdidas económicas, pero, a pesar de todo, se logró dar la sensación de que el cine colombiano había finalmente nacido. Lastimosamente, el mismo entusiasmo que había ya caracterizado otras esperanzas frustradas en la historia del cine colombiano, no podía suplir la extremada fragilidad de la estructura distributiva del cine autóctono. Incluso la Ley general de Cultura de 1997, que ratificaba el apoyo del Estado en materia de cinematografía, no representó por años una real competencia ni a la agresiva penetración del cine norteamericano y, en menor medida, mexicano en el territorio de Colombia, ni a la difusión del cine en casa. De hecho, los años 90 registraron una baja histórica en la afluencia al cine por parte de los colombianos y evidenciaron, una vez más, los problemas ligados a la distribución y exhibición: de 35 largometrajes nacionales realizados entre el 1993 y el 1999, solo 15 llegaron a la pantalla grande (aunque entre estos se encuentre un éxito internacional como La estrategia del caracol, dirigida por Sergio Cabrera, 1993). Ante tal situación, algunos directores reaccionaron trabajando en el medio televisivo o participando en coproducciones extranjeras como había ya ocurrido treinta años antes en la época de "Los Maestros".

La Ley general de Cultura pareció otra iniciativa ineficiente por parte del Estado, pero estableció las bases para que, en el 2003, se firmara la Ley 814, conocida como Ley de Cine. Esta vez el fomento cinematográfico pudo contar, entre otras cosas, con la creación de un Fondo de Desarrollo Cinematográfico, un sistema organizado de contribuciones parafiscales y el reconocimiento de la figura del productor en términos profesionales. Es así como se crearon nuevas casas de producción y se pudo pasar desde un solo largometraje producido en el 2000 a doce en el $2008^{10}$. La constante participación de la cinematografía colombiana en festivales internacionales, la alta calidad artística y técnica de muchas de sus películas y la buena acogida que el cine autóctono parece finalmente tener también en su tierra, hacen pensar que quizás la historia del cine colombiano no vuelva a conocer interrupciones ni en el breve ni en el largo término.

\section{DELIMITACIONES DEL CAMPO INVESTIGATIVO}

Por ser supuestamente fuentes de opiniones informadas y serias, las revistas especializadas representan el punto de partida de muchas investigaciones de archivo. La presente investigación no tuvo intenciones diferentes al principio, pero sí quiso desviarse en algunos

10 Entre los más destacados del período se encuentran: Soñar no cuesta nada, dir. Rodrigo Triana, 2006; Satanás, dir. Andy Baiz, 2007, y Un tigre de papel, dir. Luis Ospina, 2007. 
casos para seguir pistas nuevas abiertas por citas bibliográficas que conducían a menudo a periódicos o publicaciones no especializadas. Sin embargo, lo que se hizo está bien lejos de ser una investigación exhaustiva en periódicos. Al contrario, una mirada cuidadosa a algunos de los que tienen más larga trayectoria en el país, como El Tiempo o El Espectador, está todavía por hacerse. Si lo que se quiere es reconstruir la crónica de la vida musical que ha rodeado el cine colombiano ${ }^{11}$, pues es allí donde probablemente habría que buscarla ${ }^{12}$. Siendo nuestra meta la búsqueda de un repertorio literario menos extemporáneo, más que la colección de periódicos de las hemerotecas, el primer selector de nuestro material de partida han sido las bases de datos de las principales bibliotecas nacionales -públicas y universitarias-. Lo que siguió de allí fue un camino centrífugo para ubicar fuentes y documentos que, a pesar de alejarnos progresivamente del núcleo central, favorecían una visión cada vez más amplia y orgánica de la historia cinematográfica de Colombia desde una perspectiva musical.

La primera selección, que nos ponía inequívocamente en dirección hacia las revistas de cine y de cultura, produjo un resultado que, como ya se explicó, era en parte esperado. A una inquisición extensa de este material, añadimos entonces una pesquisa en los principales textos colombianos de cine, en tesis universitarias, en boletines de programación de radiodifusoras y, finalmente, en fuentes digitales (CD, DVD y sitios internet). Todo ello sin olvidar que los márgenes de nuestra investigación han sido desde el principio los dos siguientes: a) enfocarse principalmente en la producción de revistas especializadas y de libros; b) incluir cualquier texto que haya sido escrito para y publicado por una revista colombiana, no importa si de autor colombiano o sobre la música colombiana en el cine colombiano. Colombia se entiende aquí entonces como pueblo destinatario de una contribución cultural, y no como identidad nacional. Nos interesa más lo que se dio a leer al público colombiano en término de trabajos originales, que los límites geográficos y culturales que un texto define para su contenido. Caso aparte es la reedición en traducción castellana de textos inicialmente publicados en el exterior. Si no se han tenido en cuenta es porque su existencia, sin duda importante, se debe a decisiones editoriales y no a la voluntad de brindar un producto original para un destinatario específico ${ }^{13}$. En nuestra lista de publicaciones

11 Aunque fuese de forma indirecta como cuando la sala de cine era también, o se prestaba ocasionalmente para ser utilizada como un lugar de teatro musical (ópera lírica y zarzuela). La revista Olympia, órgano oficial del Salón Olympia, administrado por sus propietarios los hermanos Di Domenico, publicitó a menudo las compañías operísticas que pasaban frecuentemente por los escenarios del teatro ("La ópera en el Olympia", 1915: 1). Sobre el mismo tema relatan también Jorge Nieto y Diego Rojas (1992: 59-61). Una gustosa e irónica opinión acerca de la orquesta del Olympia, aunque de una ingenuidad al borde de la ignorancia en hechos musicales (y, tal vez, ortográficos), nos la da también un escritor anónimo: "En el orquesta del Olympia, que por cierto está de chuparse los dedos, hay ahora músicos de "primo cartello». Vale la pena oir [ sic] esta orquesta que sí sabe por dó va esta agua al molino en asuntos de repertorio variado. Todos los profesores están muy de acuerdo. En esto se parecen a los liberales" ("Los señores de la música”, 1919: s.p.).

12 Nos lo confirma Hernando Martínez Pardo, en dos artículos de El Tiempo citados en su libro (1978: 72). Lastimosamente, no pudimos remontar a la fuente primaria por posibles errores en las referencias bibliográficas de Martínez Pardo.

13 Aquí se reportan unos cuantos, pero podrían ser más, en vista de que no siempre ha sido posible determinar con exactitud la procedencia del material: Wiestaw Kot (trad. Bogdan Janusz), "La nueva música del cine", El Malpensante, N ${ }^{\circ}$ 16, abr. 1999, pp. 52-55 (una entrevista al compositor polaco Zbigniew Preisner); Brian De Palma, "El sonido y la furia”, El Malpensante, $\mathrm{N}^{\circ}$ 49, sept. 16-oct. 31 de 2003, pp. 68-71 (en este artículo el director habla de Bernard Herrmann); Tom Schneller, "Death and Love: Bernard Herrmann's Score for Vertigo", Cuadernos de Música, Artes Visuales y Arte Escénicas, Vol. 1, N 2, abr.-sep. 2005, pp. 189-200; Henry Colpi, "La música de 'Hiroshima, mi amor”, Boletín 
(ver Apéndice) no caben tampoco las críticas de películas de argumento musical, ya que es razonable pensar que, en su mayoría, fueron escritas no con la intención sino con la inevitable necesidad de hablar de la música para cine ${ }^{14}$.

Como ya se había anunciado precedentemente, las modalidades investigativas aplicadas al caso colombiano podrían ser, mutatis mutandi, repetidas para otros países de América Latina.

\section{4. “... UN TEMA QUE SE HA ESTUDIADO POCO EN COLOMBIA”}

La exploración de las revistas de cine ha sido enormemente facilitada por la labor documental de la Fundación Patrimonio Fílmico Colombiano (FPFC) que, con su valiosa edición comentada de las Publicaciones periódicas de cine y video en Colombia 1908-2007 (2007) ${ }^{15}$, ha empujado esta investigación hacia una conclusión más rápida de lo esperado. No podemos decir lo mismo respecto de la música, de la que no existe todavía una publicación equivalente que cubra el período histórico en cuestión. En verdad, no existe tampoco una cantidad de revistas de música en el siglo XX que pueda ser lejanamente comparable con la abundancia de publicaciones de cine, pues hay 127 revistas contenidas en el texto de la FPFC.

Por supuesto, una buena parte de estas revistas tuvo vida muy breve ${ }^{16}$ y fue más el fruto de buenas intenciones de irreductibles aficionados o pequeños cineclubes universitarios, que el resultado de una empresa editorial sólida y organizada. De todas maneras, el dato no deja de sorprender, y asombra incluso más si, como ya se mencionó en el apartado 2, se considera que el cine en Colombia ha sido caracterizado (por lo menos hasta hace poco) por una historia de discontinuidades productivas ${ }^{17}$, de falsas promesas y esperanzas desatendidas, de soñadores inspirados y de sonoros fracasos comerciales ${ }^{18}$, de ayudas estatales y mala gestión de los aparatos legislativos y económicos; en fin, una historia hecha de tanta buena voluntad por parte de pocos y muchas coyunturas adversas.

La importancia de las revistas de cine reside en el hecho de que son ellas las que albergan la mayoría de artículos relacionados con la música para películas. Desafortunadamente, pocos de estos artículos (a modo de ejemplo Lugo Febres 2006: 46-51; Camuñas 1988:

de Programación de la Radiotelevisora Nacional de Colombia, $\mathrm{N}^{\circ}$ 193, ago. 1960, pp. 18-24 (primera parte) y No 194, sept. 1960, pp. 21-24 (segunda parte) [el autor es el bien conocido especialista francés de música para cine y autor del libro Défense et illustration de la musique dans le film (Lyon: SERDOC, 1963) ]; [Graham Bruce], "La música en los filmes de Glauber Rocha”, Arcadia va al cine, № 1, mar.-abr. 1982, pp. 9-15 (originalmente publicado en Jump Cut, $\mathrm{N}^{\circ} 22$, mayo 1980, pp. 15-18); y consideraciones sobre el sonido, extraídas de textos del célebre teórico y escritor húngaro Béla Bálazs, en Consecuencias, $\mathrm{N}^{\circ} 5$, 2007, pp. 23-31.

14 Entran en esta categoría las penetrantes críticas de Luis Alberto Álvarez a "La Flauta Mágica de Mozart y Bergman", "Sobre María Callas, el cine y la ópera", "El maestro de música de Gérard Corbiau: el misterio del secreto inaferrable”, etc. La única excepción es la "Conversación con Luis Bacalov: la música es más importante de lo que nosotros sabemos” (Álvarez 1992, Vol. 2: 243-264).

$15 \mathrm{Y}$, sobre todo, con el archivo físico guardado en la sede bogotana de la fundación.

16 Muchas son las revistas que no lograron publicar sino pocos números, por ejemplo: Boletín (1976), Cine-búho (1980), En Rodaje (1984), Super 8 (1984), Claqueta (1986), etc.

17 Las reflexiones críticas "Siempre [...] surgen después de hacer la película; además, como pasa a menudo, de película en película se van cinco años. Lo más grave de América Latina en el cine es la distancia con que se trabaja, porque se elabora y se desarrolla en el pensamiento, pero nunca en la práctica”. Así lamenta Carlos Álvarez en una entrevista del 19 de junio de 1977 con Umberto Valverde (Valverde 1978: 71).

18 Nos referimos aquí a la turbulenta vida de Camilo Correa, crítico, director y empresario de Medellín (Duque 1988; texto que después fue incluido en una versión abreviada en Duque 1992: 296-374). 
47-48) emergen desde una difusa mediocridad que, con demasiada frecuencia, equivoca la divulgación con una injustificada chabacanería y negligencia en brindar informaciones precisas y correctas. Incluso la revista Kinetoscopio, una de las más duraderas en Colombia (ya cuenta con veintidós años de existencia) y la que más que cualquier otra ha publicado artículos de la música para cine (siete), no parece haberse preocupado mucho, ni de la calidad, ni del contenido de estos trabajos ${ }^{19}$, salvo en pocos e insustanciales $\operatorname{casos}^{20}$. Sin embargo, entre las revistas de cine se encuentra una pequeña joya de la que hablaremos en el capítulo sobre las fuentes de particular interés (apartado 5).

Desde el mundo musical no se han encontrado casi aportaciones, excepto por unos pocos artículos de menor valor y el interesante CD El cine colombiano en música que Carlos Barreiro Ortiz editó en el 2005, el único de su estilo existente hasta el momento. A la publicación del CD y su cuadernillo, se acompañaron también un artículo escrito para $E l$ Tiempo (2005a: s.p.), una edición separada y parcialmente modificada del mismo cuadernillo (2005b) y algunas conferencias. Barreiro Ortiz fue, sin duda, el único investigador colombiano en haber prestado atención duradera a la música que los compositores de su país han escrito para el cine ${ }^{21}$. Sin embargo, puede con razón afirmarse lo que se puso como título de este apartado ${ }^{22}$. En efecto, lo que se acerca más a una contribución investigativa, después de su experiencia, son algunas tesis de pregrado procedentes de la carrera en Comunicación Social de la Universidad Pontificia Bolivariana (UPB) en Medellín y del énfasis en Composición de Música Comercial que se ofrece en la carrera de Estudios Musicales de la Pontificia Universidad Javeriana (PUJ) en Bogotá. De la PUJ salieron seis tesis de pregrado escritas entre el 2005 y 2010 (ver lista de las publicaciones, tesis de pregrado) a las que es posible añadir un unicum más curioso por su datación que por su contenido: El papel de la música en un medio de comunicación social: el cine, de Magaly Rosales de Gómez. Esta tesis fue escrita en 1976 para la Licenciatura en Ciencias de la Comunicación Social (hoy simplemente Comunicación Social) de la Universidad Javeriana. Como era de esperar, tiene un enfoque eminentemente comunicacional, con posiciones estéticas muy cuestionables. Se destaca, de todos modos, el "pionerismo" de la autora (y su asesor, Enrique de la Hoz Díaz) en haber escogido como objeto de tesis un tema que, en ese tiempo, era de poca acogida académica, incluso en países con tradiciones músico-cinematográficas mucho más largas que Colombia.

Así como ocurrió en este último caso, también en la UPB las contribuciones estudiantiles acerca del tema no provienen de una carrera en música o en cinematografía, sino de estudios de comunicación que, por su amplio espectro disciplinario, contemplan también el cine y su música (ver Apéndice).

Curiosamente, música y cine son dos temas que se han mantenido cuidadosamente separados en el tiempo, incluso en publicaciones que harían pensar exactamente lo contrario. Quizás el caso más elocuente sea el de los diecisiete números de Cine y Música (un

19 Entre enero de 1994 y junio del año siguiente, Kinetoscopio publicó tres artículos que tratan, bajo títulos diferentes pero con igual superficialidad e irreflexión, un tema demasiado extenso para caber en pocas páginas: la historia de la música para cine.

20 Insustanciales porque el formato mismo de la revista no permitió a los autores un mayor desarrollo de los temas tratados.

21 De hecho, el artículo de El Tiempo online que acabamos de citar es precedido por otros tres del mismo autor (ver artículos en revistas, 1996 y artículos en periódicos), todos publicados a mediados de los años noventa, como demostración de un interés más que decenal de Barreiro Ortiz por el tema. A estos, hay que añadir el más reciente "Luis Antonio Escobar. Un compositor para el cine colombiano" (2006: 111-113).

22 De acuerdo con comunicación vía email de Carlos Barreiro Ortiz con el autor. 
suplemento dominical del periódico medellinense $E l$ Mundo), los que en ningún momento reflexionan pertinente a la unión de las dos artes, prefiriendo guardarlos en una zona de más "seguro" aislamiento. También la revista Micro del inquieto Camilo Correa, a pesar de haberse dedicado a programas radiales, cine, música y deporte, solo una vez en sus sesenta y dos números trata de la música para películas. Cuando lo hizo fue en un caso muy especial e irrepetible: Fantasía de Walt Disney, un "concierto ilustrado", como lo define el distinguido autor de la reseña (Zulategui 1943: 11-44). Un último ejemplo, menos contundente pero no por esto menos significativo, es el del Boletín de Programas de la Radiodifusora Nacional23. En sus tres décadas de publicación, no faltaron artículos de cine, lo que es coherente con el haber tenido en la parrilla por muchos años un programa con este tema ${ }^{24}$. Más difícil de entender es por qué del programa que le seguía, y que tenía el inequívoco título de "Música para el cine" 25 , no haya salido ningún escrito, salvo la traducción del ensayo de Colpi, mencionado en la nota 13. Sin embargo, la sola existencia en la radio de los años 1950 de un programa de la música para cine es un hecho suficiente para llamar la atención de una investigación más dirigida, sobre todo cuando se considera que, a pesar de ser un fenómeno muy raro, no es completamente aislado 26 .

El estatus intermedio, indefinido, por así decirlo, de la música para cine, ha creado desde siempre problemas de colocación editorial, los que, en muchos casos, han sido resueltos recortando espacio en las revistas de cultura general, o sea, en un terreno heterogéneo, muy cercano a la misma naturaleza del cine. Es exactamente aquí donde encontramos casi la mitad de las publicaciones de la música para películas, aunque, en algunos casos, los autores son los mismos que firman ensayos también en las revistas de cine, a modo de ejemplo: Hugo Chaparro Valderrama, Juan Diego Caicedo González y Ricardo Silva Romero. Encontramos también a Carlos Barreiro Ortiz, cuya preparación interdisciplinaria le permitía escribir indiferentemente en una revista de cine o en la sección musical de un periódico. Es así como, en la Revista de la Universidad de Antioquia, publica un breve homenaje a un compositor cuya producción cinematográfica necesita ser estudiada todavía, porque Luis Antonio "Escobar fue uno de los primeros compositores colombianos de formación académica que aceptó el reto de escribir música original para el cine" (Barreiro Ortiz 2006: 111).

Otro caso llamativo es el de Juan Diego Caicedo González, profesor en la Escuela de Cine y Televisión de la Universidad Nacional de Colombia, quizás el único en intentar un largo ensayo de carácter filosófico-estético que finalmente desemboca en una breve historia

23 El mismo boletín ha cambiado de nombre dos veces. Desde el número 143 (junio 1956, en coincidencia con el comienzo de la televisión colombiana) empezó a llamarse Boletín de Programas de la Radiotelevisora Nacional de Colombia. Este boletín terminó su publicación en 1966 y volvió a aparecer en 1969, con un nuevo nombre y numeración: Boletín de Programas de la Radio Nacional de Colombia.

24 Ya en febrero de 1954 aparece "Crítica del cine" por Ernesto Volkening, los lunes de 9 a 9:15 de la noche con repetición los martes de 9 a 9:15 de la mañana. Por falta de material documental, no pudimos establecer con exactitud la fecha exacta de la primera emisión del programa, la que seguramente no se remonta a un período anterior a 1950.

25 Nace contemporáneamente a "Crítica del cine" y sale al aire los mismos días en el cuarto de hora siguiente. Nunca se indica de quién es la curaduría, por lo que nombrar al mismo Volkening es mera suposición. Contrariamente a "Crítica del cine", "Música para el cine" tuvo una vida relativamente breve y desapareció a los pocos años. El lunes 2 de abril de 1956 fue remplazado por "Conciertos de las Naciones Unidas".

26 Así lo demuestra el programa de la Emisora Cultural de la Universidad de Antioquia (Medellín), "Banda sonora", el que, desde 1998, Daniel Rodríguez Vidosevich y María Isabel Galvis Zúñiga han venido conduciendo en los días festivos, de $6 \mathrm{pm}$ a $7 \mathrm{pm}$. El autor del presente artículo fue invitado a hablar de los primeros alcances de la presente investigación en el programa emitido el 20 de julio del 2012. 
de la música para cine y en una lista comentada "Sobre autores cinematográficos y compositores" (Caicedo González 1995: 97-132). Finalmente, en la revista Lámpara, al lado de un decepcionante artículo de Bernardo Hoyos Pérez (1995: 31-35), hay un breve comentario del destacado compositor colombiano Blas Emilio Atehortúa acerca de la música del documental La ciudad ${ }^{27}$ (1971: 21-22). No es obviamente -y solo- la fama del compositor lo que hace sus observaciones dignas de interés, sino la claridad y la firmeza con las cuales Atehortúa, a pesar de no ser un especialista del género, establece principios compositivos en línea con las mejores tradiciones de música aplicada al cine. Su inteligencia musical se distingue en las bandas musicales que llevan su nombre y de las que habla en el documental autobiográfico Blas: El hombre y su leyenda (Likosova y Restrepo 2008) ${ }^{28}$. Siempre aquí aflora, de las palabras del compositor, una concepción simultánea de la música como arte y artesanía, labor y trabajo, cosa que explica el porqué de su natural predisposición y sano pragmatismo en la composición para la imagen.

También en las revistas de cultura se encuentra un pequeño tesoro del que vamos a hablar en el apartado siguiente.

\section{FUENTES DE PARTICULAR INTERÉS}

Se trata aquí de dos de las fuentes más antiguas; una procedente de una revista de cine, la otra de una revista de cultura, las que corresponden a los siguientes autores: Alberto Urdaneta Forero, "La tragedia del silencio. Valse de la selección para la película del mismo nombre" (listado de las publicaciones, artículos en revistas, 1924: s.p.), e Ignacio Isaza Martínez (artículos en revistas, 1937: 10-14; 2014: 87-9129).

La publicación de Cine Colombia está firmada por González Coutín, un doctor en medicina general y director de un "Laboratorio de Bacteriología y Química Biológica" 30 , este redactó una "Novela Cinematográfica" para el primero y único número existente de la revista (conservada en la sede de la FPFC). Como se lee en las Publicaciones periódicas y en Pedro Adrián Zuluaga (2007: 41), la revista fue creada "con el objetivo de publicar 'las novelas de las películas de la Casa Cinematográfica Colombia", y no tiene "alguna relación con la homónima distribuidora de películas” (FPFC 2007: 9), la que pocos años después (1927) empezó su casi secular negocio cinematográfico. El primer número de Cine Colombia tuvo una función propagandista y fue dedicado a "destacar la fundación de la casa productora y del estreno del largometraje La tragedia del silencio" (FPFC 2007: 9). Su particularidad es ser, que se sepa con certeza, la única película del período mudo colombiano en haberse beneficiado de una partitura original. Una veintena de hojas, con un tanto elaborado y curioso diseño de página, se destinaron a la publicación de la primera parte (prólogo y cuatro capítulos) de la homónima novela cinematográfica, o sea, de la versión literaria (no el guion) de la película.

Lo que más llama la atención de nosotros son cuatro páginas que se publicaron intercaladas en el texto y que señalan el ya mencionado vals de Urdaneta Forero. Urdaneta (Ubaté-Cundinamarca, 1895-Madrid, 1953) fue autor de música popular y se volvió muy conocido en 1925 por su Guabina chiquinquireña, obra que se incluyó también en la selección

27 Dir. Guillermo Angulo, prod. Cine Visión, 1971.

28 En realidad, Atehortúa comenta solo algunos aspectos de la banda musical de Edipo alcalde, dir. Jorge Alí Triana, 1996.

29 La publicación de 2014 es la traducción al inglés del escrito de Isaza Martínez, realizada e introducida por el mismo autor del presente artículo (Isaza Martínez 2014: 87-91).

30 Según se señala en algunos recuadros publicitarios de la revista. 
de piezas musicales para la película La divina aventurera" . "Sin embargo, el interés de este compositor sobrepasaba la música popular: su preocupación era crear 'música escénica' y su afán era el de afianzar una tradición nacional que le hiciera contrapeso a las compañías de zarzuela y variedades que visitaban el país" (FPFC 2009?: 21).

El vals para La tragedia del silencio, una película melodramática en el estilo del film d'art francés e italiano que era dominante en ese tiempo en Colombia (y no solo allí), es posiblemente una reducción para piano y violín de una partitura orquestal, como parecen indicar los trémolos en el piano al principio y al final, y el hecho que una película de mucha resonancia para la época debe de haber gozado de un acompañamiento orquestal, por lo menos en su estreno. Es fácil notar los numerosos errores "ortográficos” y tipográficos contenidos en la partitura (notas equivocadas, armonías no funcionales en un contexto claramente tonal, alteraciones omitidas o descuidadas, etc.), cosa que no debería sorprendernos, pues son comunes en muchas partituras de la época (ver ejemplo 1) ${ }^{32}$.

También el hecho que se trate de un vals es algo muy usual, considerando que, si el paisajismo ha sido el marco principal de casi todas las películas colombianas hasta todos los años 1940, el costumbrismo y el folclorismo (particularmente el musical) han proporcionado buena parte de sus contenidos. Es el mismo Urdaneta quien lo confirma en una reseña de Flores del valle (dir. Máximo Calvo, 1941): “Esta sí es una película colombiana! Ella traduce fielmente el ambiente y las costumbres de ese paraíso de nuestro suelo que se llama Valle del Cauca. Los paisajes son regios y captados con arte y maestría. La música ejecutada con sencillez instrumental, pero con refinado gusto, agrada y convence, porque traduce el sentimiento y la poesía del bello jirón de la tierra colombiana" (Urdaneta citado en FPFC 2007: 55) ${ }^{33}$.

Siendo generalmente la clase medio-alta la que se retrata en las películas, es obvio que formas más populares de música dejasen el espacio a las que, por tener origen europeo o, en general, foráneo, eran consideradas más cultas: arias operísticas, piezas famosas de repertorio clásico, valses y sus afiliados. A estos se agregan el bambuco y el pasillo por ser representativos de la identidad musical nacional, aunque no necesariamente de origen culto, como es el caso del bambuco. Con esto se nutrieron por décadas las bandas musicales del cine colombiano, de modo que no podían faltar nunca en las películas argumentales los números de canto y de baile ${ }^{34}$. Un bambuco vale un millón (dir. Luis David Peña, 1938), Flores del valle y Allá en el trapiche (dir. Roberto Saa Silva, 1943), y Bambucos y corazones (dir. Gabriel Martínez, 1945), todas contienen números musicales, como en algunos casos los mismos títulos declaran. En el período del cine mudo esto tenía que ocurrir con cierta frecuencia, ya que, como cuenta Hernando Salcedo Silva, "en algunas [películas] había bailes nacionales o de salón, lo que es de suponer que fueron 'sincronizados' con su música

31 Se trata, con cierta seguridad, del musical Belle of the Yukon (1944), dir. William A. Seiter. De los pocos datos biográficos de Urdaneta (Zapata Cuéncar 1962: 172; Áñez 1968: 219-220; Perdomo Escobar 1980: 238) se deduce que el compositor no tiene ninguna afiliación ni con el general y grabador Alberto Urdaneta Urdaneta (que nació cincuenta años antes) ni con su familia.

32 Juan Fernando Velásquez Ospina, que ha estudiado en detalle el repertorio publicado en revistas medellinenses del principio del siglo pasado, habla por ejemplo de costumbres "muy difundidas en la época, de solo indicar una vez las anotaciones cuando se presentaban en un compás, obviándolas en el cambio de octava" (2012: 77).

33 La reseña de Urdaneta se publicó inicialmente en el periódico El Siglo del 14 de julio de 1943.

34 De hecho, una escena de baile aparece en los fragmentos de la película de Arturo Acevedo que Jorge Nieto montó en su documental Más allá de la tragedia del silencio (VHS, prod. ESSO ColombianaIntercol y FPFC, 1987). En el trabajo de Nieto se puede apreciar una ejecución del vals de Urdaneta por Mariana Posada (piano) y Alfredo Hernández (violín). 


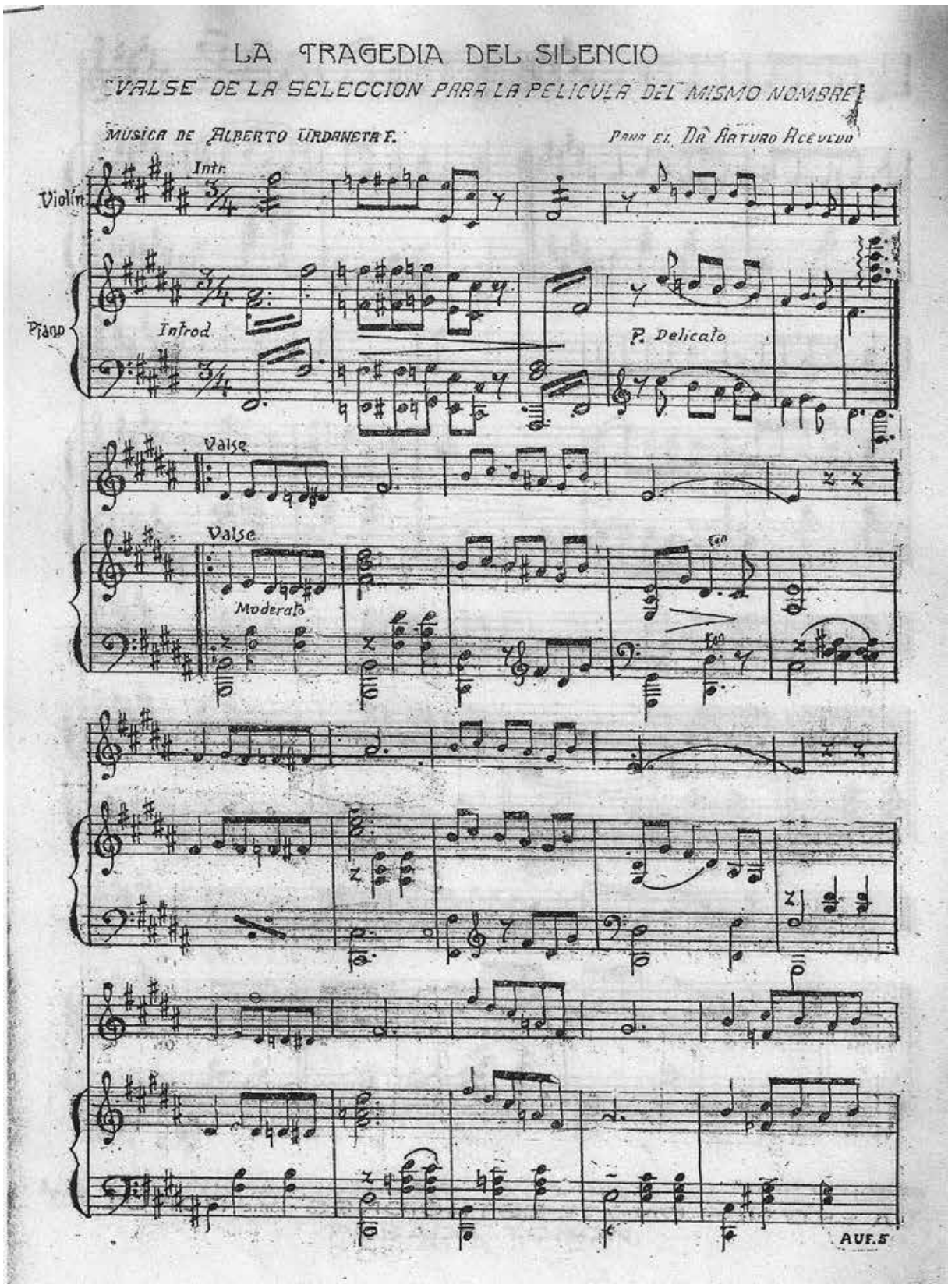

Ejemplo 1

Alberto Urdaneta Forero-Vals. 
más o menos correspondiente, y no sería demasiado raro que algún compositor hubiera trabajado en danza, bambuco o pasillo, especialmente para determinada película del periodo mudo colombiano" (Salcedo Silva 1981:141) ${ }^{35}$. Es en este contexto donde hay que inscribir entonces la pieza de Urdaneta para la selección musical de la película de Acevedo Vallarino.

El escrito de Ignacio Isaza Martínez se publica en un año significativo para el cine colombiano, pues en 1937 se estrena la primera obra de cine parlante nacional: Olaya Herrera y Eduardo Santos, por la Casa Cinematográfica Acevedo \& Schroeder. El sistema audiovisual inventado por el ingeniero colombo-alemán Carlos Schroeder y su colaborador César Estévez había dado su primera tímida pero exitosa prueba pública ya en 1929. Sin embargo, en una versión perfeccionada, hizo su debut muchos años después, exactamente cuando los Acevedo decidieron realizar un documental con ocasión de la muerte del expresidente liberal Olaya Herrera y la subida al poder de su seguidor Eduardo Santos (Martínez Pardo 1978: 71-80).

En la euforia del nuevo cine sonoro encontraron espacio las avanzadas reflexiones de Isaza Martínez, un ingeniero antioqueño y fundador, con Marco Peláez, de la Sociedad de Amigos del Arte de Medellín ${ }^{36}$. El espacio lo ofreció Revista "Pan", emisión editorial de un grupo de intelectuales caucanos (Popayán) quienes, en tonos vagamente dadaístas y bajo el nombre colectivo de Nabisco, decidieron crear y publicar, en agosto de 1935, el primer número de este órgano cultural. La revista se imprimió inicialmente en Cali, pero ya a partir del tercer número fue trasladada a Bogotá, aparentemente sin perder con los años su aire burlón. En el encabezado del artículo, el editor, después de alabar a Martínez ("un cineasta, profundo y apasionado conocedor de la materia"), cierra diciendo que al autor "ha prometido seguir discutiendo en estas páginas las relaciones del Arte del Cinema con los diversos aspectos de la vida moderna ... y suministrar al Editor algunas ilustraciones de su colección ... Ojalá" (Isaza Martínez 1937: 10). El tono del artículo de Martínez, al contrario, es mucho más serio y analítico, o, mejor dicho, es el único, entre todos los materiales encontrados en esta investigación, que propone una visión analítica de la relación música/imagen.

Después de haber recordado que Thomas Alva Edison inventó el kinetoscopio para proveer imágenes a la música reproducida por su fonógrafo y volverla más interesante para el oyente, Isaza Martínez señala que, treinta años después, la situación está trastocada: ahora es el cine quien necesita la música, así hace que sus imágenes sean más interesantes para el vidente. Imágenes (en movimiento) y música van a constituir entonces una forma de espectáculo que se origina de "las mismas fuerzas que hicieron nacer el teatro, la ópera, el ballet ruso" (1937: 10). El cine es, por tanto, "el resultado de un fenómeno natural y constante" (1937: 10), según una visión organicista de la historia que durante todo el período silente generó terribles malentendidos acerca de la autonomía del cine respecto del teatro. Pero Isaza Martínez no cae en una equivocación tan burda, sino que propone, en cambio, una cuestión más actual por los tiempos en que escribe: "Si el cine sonoro es o no un arte nuevo, fundamentalmente distinto del cine mudo" (1937: 10). Que después decida abiertamente no discutir el asunto, es porque quiere brindar una más sutil y, quizás, resolutoria discriminación (Isaza Martínez 1937: 10):

35 Por el tono hipotético del comentario, se infiere que el autor no tenía conocimiento de la partitura de Urdaneta publicada en Cine Colombia.

36 Más informaciones de Isaza Martínez en Fernando Gil Araque (Ed.). Biblioteca digital de música, sección Biografias. URL http://www.bdmusica.eafit.edu.co/biografias/biofor?id=BDM\%20O00051. 
Tal vez se aclararía el tema separando el cine puramente sonoro del cine parlante. Porque es evidente que al emplear la voz de manera sistemática, el cinema entregó cualidades artísticas de primer orden. Perdió internacionalismo; relegó a segundo plano la mímica; hizo que muchos encuadres se alargaran para dar campo al diálogo; convirtió el tiempo fílmico en tiempo real; dificultó el montaje y la yuxtaposición de las escenas.

Es indiscutible que, para Isaza Martínez, no caben dudas de la autonomía artística y expresiva del cine, una independencia que el abuso del diálogo y, consecuentemente, el frecuente regreso a un modelo teatral-literario del cine en los primeros años 1930, parecían a veces poner en peligro. Lo que el autor sí lamenta es un deplorable desorden y casualidad en el acompañamiento musical de muchas películas ${ }^{37}$. Así que, para poner orden a este uso "irracional", un orden tal vez sugerido por su formación científica de ingeniero, Isaza Martínez plantea un distingo analítico basado en dos relaciones dialécticas que pueden establecerse entre música e imagen: paralelismo y contrapunto. Esta articulación del discurso audiovisual es de obvia ascendencia eisensteiniana. Y que Isaza Martínez conociera directa o indirectamente las teorías del director ruso respecto del montaje se deduce de sus citas de Paul Rotha, director inglés cuya formación teórica se debía a los ensayos de Vertov y Pudovkin (el que, como es sabido, fue signatario con Eisenstein y Alexandrov del a veces llamado "Manifiesto sobre el cine sonoro" o "Manifiesto del contrapunto sonoro"). Finalmente, después de haber sugerido que el mejor resultado es alcanzado por un uso equilibrado de paralelismo y contrapunto, Isaza Martínez propone una tercera vía -el silencio- "Porque si hay pasajes que se engrandecen con un motivo musical, hay también otros que no toleran el más leve sonido" (1937: 12).

Mucho más cuestionables son ciertas consideraciones que el autor hace respecto del musical. En su lectura del género, Isaza Martínez manifiesta toda su incapacidad de ver en él algo más que una simple unión "del sonido y del diálogo" o, peor todavía, "un espectáculo hecho sin pretensión alguna de arte y solamente con el fin preconcebido de divertir" (1937: 12-14). En la misma cuenta caen también las películas en las cuales "se cuenta la accidentada carrera de una supuesta gran cantante que logra al fin llegar a la Scala, o al Metropolitan" (1937: 14), o sea, los biopics relativos a personajes históricos o de invención. Con cierto fundamento y sin mayor giro de palabras, el autor define estas obras como "Colecciones de lugares comunes, tratados de mal gusto, demostraciones de arte falso" (1937: 14), y manifiesta su abierta desaprobación del modo en que se han desperdiciado muchos talentos del canto lírico para servir películas de ínfimo valor. Concluye el artículo con un comentario crítico-moral acerca del mal uso que se hace de muchas obras maestras de la música ${ }^{38}$.

Con su ensayo, Isaza Martínez nos deja una aguda, por cuanto breve, reflexión que lastimosamente no ha producido ulteriores profundizaciones, ni por parte del autor mismo, ni por parte de otros. En las décadas de 1950 y 1960, junto a la administración de la Sociedad Amigos del Arte, Isaza Martínez se interesó principalmente en el folclorismo (1951; 1966: 35-37).

37 "Casi todas las películas tienen un acompañamiento musical hecho de retazos, sin orden y sin método, carente en absoluto de racional conexión con lo que se proyecta” (Isaza Martínez 1937: 12).

38 "Es falta de honradez artística mixtificar de esa manera el gusto del público, habiendo en música tántas [sic] obras maestras que podrían explotarse con éxito en el cinematógrafo" (Isaza Martínez 1937: 14). 


\section{CONCLUSIONES}

El crítico cinematográfico antioqueño Orlando Mora atribuye la falta de literatura de la música para cine en Colombia a la ausencia de una verdadera industria cinematográfica que permita una mayor continuidad productiva y la necesidad de personal especializado ${ }^{39}$. Si bien no están del todo ausentes figuras de compositores particularmente dedicados (como Germán Arrieta y, en forma más esporádica, los ya mencionados Escobar y Atehortúa), se supone que la Ley de Cine, al favorecer el mercado productivo interno, conlleve la demanda de un siempre mayor nivel de profesionalismo. A esto se añade la perspectiva futura de crear estudios cinematográficos en Medellín para "el rodaje de filmes de tipo Hollywood" (Montoya 2012: s.p. ${ }^{40}$, de estos se beneficiarían no solo la economía de la región y del país, sino también todo un sector de trabajadores potenciales o reales que quieran prepararse para una carrera en la industria cinematográfica o que necesiten reforzar sus conocimientos y habilidades. Es razonable pensar que esto pueda estimular, entre otras cosas, más carreras universitarias en música para cine y, consecuentemente, más compositores que hagan de la música aplicada a la imagen su primera ocupación. Sin embargo, mientras anhelamos que esto ocurra, habría que volver a dar una mirada al pasado para reconstruir la vida musical que, durante un siglo de historia, giró alrededor del rodaje y proyección de las películas colombianas. De la misma manera, como se sugirió ya al principio del presente artículo, habría que estudiar las relaciones entre compositores y directores, hacer una revisión crítica del trabajo de compositores que estuvieron, y todavía están, activos en el cine colombiano (prosiguiendo así el camino indicado por Barreiro Ortiz), elaborar análisis de las partituras de películas específicas, etcétera.

Esperemos que estos, y otros relacionados, sean los temas que animen futuras investigaciones...

\section{APÉNDICE}

\section{Lista de las publicaciones}

A pesar del interés primario en artículos de revistas y capítulos de libros, listamos aquí también los artículos en periódicos y las tesis universitarias encontrados durante nuestra búsqueda, recordando que estos tipos de materiales necesitan todavía una investigación específica.

Para la lectura de la siguiente bibliografía se considera que todas las entradas, por cada tipo de publicación, están en orden cronológico (y alfabético si hay más publicaciones en el mismo año). Las letras que aparecen después de los números de páginas en cada entrada de artículos de revistas señalan: $\mathrm{M}$, revista de música; $\mathrm{C}$, revista de cine; $\mathrm{U}$, revista de cultura. Los artículos acerca de los cuales queda la duda de si son traducciones o reproducciones de trabajos publicados anteriormente fuera de Colombia, están marcados con un asterisco que precede el nombre del autor. Los números entre corchetes al final de una entrada indican la categoría temática a la que el artículo pertenece, según la siguiente tabla de correspondencias:

1) Historia de la música para película

2) Estética de la música para película

39 Comunicación personal con Orlando Mora.

40 En la fecha en que salió el artículo de Montoya, se hablaba de un posible interés por parte del grupo inglés Pinewood Studios. 
3) Compositores de música para película

4) Música para películas escrita por bandas de música pop, rock, etcétera.

5) Film-ópera

6) Bandas musicales específicas

7) Crónicas personales

8) Entrevistas

9) Reseñas

10) Partituras

Esta organización por categorías -aplicada solo a los artículos en revistas- no hay que tomarla con rigidez, pues la categoría "Estética de la música para película" incluye ensayos que solo en sentido amplio hablan de estética. Por otra parte, la pertenencia a una categoría no es única, ya que algunos artículos se proponen abarcar más aspectos de la música para cine -y, por esta razón, llevan más de un número entre corchetes-.

Las tesis universitarias concebidas solo como producto compositivo, o sea, sin el soporte de un texto escrito, no se han tomado en consideración.

\section{ARTÍCULOS EN REVISTAS}

Urdaneta Forero, Alberto

1924 "La tragedia del silencio. Valse de la selección para la película del mismo nombre", Cine Colombia, s.n., s.p. C [10]

IsAza Martínez, IgNAGio

1937 "El cinema y la música", Revista "Pan", No 17, pp. 10-14. U [2]

Atehortúa, Blas Emilio

1971 "Música de la película”, Lámpara, Vol. 15, No 72, pp. 21-22. U [2]

*González, William y Rafael Quintero

1978 "Música antillana en el cine cubano", Cuadro, No 7, pp. 10-18. C [6]

Aconcha, Roberto

1981 "Música para cine", Cine Colombiano, s.n., p. 16. C [2]

* O’Toole, Lawrence

1982 "El calor de la música", Cine, No 8, pp. 37-49. C [1]

Macía Mejía, Rafael

1983 “Pink Floyd, imagen y sonido", Secuencia, No 5, pp. 21-22. C [4]

Giraldo Neira, Armando

1984 "La música en el cine", Documento Cinematográfico Latinoamericano, No 17, p. 48. C [2]

"Ennio Morricone"

1987 Toma 7, $\mathrm{N}^{\circ} 55$, pp. 46-47. C [3]

* Camuñas, Carlos Rafael

1988 "En defensa de la música cinematográfica", Documento Cinematográfico Latinoamericano, $\mathrm{N}^{\circ} 10$, pp. 47-48. C [2]

Bardwell, Paul

1993 "Entrevista con Irma Hughes. 'El cine sonoro fue un truco vil”, Kinetoscopio, Vol. 4, $\mathrm{N}^{\circ} 20$, pp. 50-53. C [8] 
Arteaga, José

1994 "El sonido de las bandas", 91.9: la revista que suena, Vol. 0, No 2, pp. 3-5. M [1]

Escobar Giraldo, Octavio

1994 “Cristales del tiempo", Kinetoscopio, Vol. 5, No 25, pp. 125-127. C [9]

VAlencia, Jorge

1994 "Lo que se puede ver con los ojos cerrados", Kinetoscopio, Vol. 5, № 23, pp. 43-51. C [2]

Caicedo González, Juan Diego

1995 "Música-Cine: vínculo indisoluble", Ensayos, Nº 2, pp. 97-132. U [2]

Chaparro Valderrama, Hugo

1995 "La música muda del cine”, 91.9: la revista que suena, Vol. 0, № 8, pp. 44-45. M [1,2]

Giraldo, Carlos Augusto

1995 “Al ritmo de tus ojos”, Kinetoscopio, Vol. 6, No 31/32, pp. 74-78. C [1]

Hoyos Pérez, Bernardo

1995 “La música y el cine”, Lámpara, Vol. 33, No 127, pp. 31-35. U [7]

Barreiro Ortiz, Carlos

1996 "Compositores colombianos en el cine nacional”. Kinetoscopio, Vol. 7, N 36, pp. 96-99. C [1]

GonzÁlez A., Juan Carlos

1998 "El cine según Gershwin”, Kinetoscopio, Vol. 9, º 48, pp. 10-15. C [3]

Olaya Vargas, César Augusto

1998 "La banda sonora", Agenda Cultural, No 40, pp. 10-12. U [1,2]

Pérez Duque, Ángela María

1998 "Notas para una rosa”, Agenda Cultural, № 40, pp. 13-15. U [8]

Moreno S., Claudia

2000 "Los sonidos de la imagen”, Fábula, N 4, pp. 24-29. C [2,3]

Salazar Carvajal, Erick

2000 "La prosa musical de Kaurismaki”, Ciudadano Caín, № 1, pp. 70-71. C [6]

URiBe, Nicolás

2002 "El diálogo entre el director y el compositor", Kinetoscopio, Vol. 13, No 64, pp. 72-73. C [2]

Chaparro Valderrama, Hugo

2003 "El jazz de las imágenes en movimiento", Yesca y Pedernal, Vol. 1, No 4, pp. 67-76 $\mathrm{U}[1,2$ (sociológico) $]$.

Barreiro Ortiz, Carlos

2006 "Luis Antonio Escobar (1925-1993). Un compositor para el cine colombiano", Revista Universidad de Antioquia, $\mathrm{N}^{\circ}$ 283, pp. 111-113. U [3]

Lugo Febres, Martín

2006 "Reflexiones sobre las implicaciones del sonoro", Consecuencia, № 4, pp. 46-51. C [2]

Rendón Jaramillo, Catalina

2006 "Bandas sonoras: música para poner los pelos de punta", Revista Música, № 10, pp. 22-23. M [1] 
García-Berrío Hernández, Antonio

2007 "Música, la emoción del cine”, Revista de occidente, № 308, pp. 92-112. U [3]

Silva Romero, Ricardo

2007 "Spaghetti Morricone", Arcadia, No 17, p. 30. U [3]

Peña Riveros, Mauricio

2008 “Alma sonora”, Publicidad y Mercadeo (PEM), Vol. 32, N 324, pp. 40-43. U [8]

Capítulos de libros

Álvarez, Luis Alberto

1992 "Conversación con Luis Bacalov: la música es más importante de lo que nosotros sabemos”. En Luis Alberto Álvarez. Páginas de cine, vol. 2. Medellín: Universidad de Antioquia, pp. 243-264.

Caicedo González, Juan Diego

2009 "Las afinidades electivas entre el cine y la música". En Juan Diego Caicedo González. Sobre el cine y sus hermanas. Bogotá: Universidad Nacional de Colombia, Facultad de Artes (el escrito tiene mínimas modificaciones con respecto al mismo artículo publicado por Caicedo González en la revista Ensayos), pp. 105-135.

Artículos en periódicos

"LA MÚSICA EN EL Olympia"

(autor no determinado) ${ }^{41}$ El Tiempo, p. 5.

"Música en el Cine"

(autor no determinado) ${ }^{42}$ El Tiempo, p. 3.

Barreiro Ortiz, Carlos

1994 "Música: poesía en el cine”, El Tiempo (2 de enero), p. 15b.

1994 “Al cine criollo con su música”, El Tiempo (6 de febrero), p. 11c.

Bello, Gilberto

1995 “Música, cámara, acción”, El Espectador (9 de julio), p. 3c.

Restrepo SÁnchez, Gonzalo

1995 “Cine y ópera. Historia de una pasión”, El Heraldo Dominical (2 de julio), p. 12.

Borja M., María del Pilar

1996 "Blas Emilio Atehortúa, los sonidos del drama", Vanguardia Dominical (18 de agosto), p. 7.

Zambrano, ANDrÉs

1996 "La banda sonora de Hollywood", fascículo Cultura de El Tiempo (15 de septiembre), p. 10c.

Caicedo González, Juan Diego

1998 "Música-cine: vinculo indisoluble", El Nuevo Siglo (15 de marzo), pp. 10-11 (publicado sin el consentimiento del autor y solo parcialmente. La segunda parte

41 En Martínez Pardo (1978: 72) aparece con fecha errada del 1 de noviembre del 1919.

42 En Martínez Pardo (1978: 72) aparece con fecha errada del 1 de noviembre del 1941. 
del ensayo, supuestamente planeada para la edición del siguiente domingo 22 de marzo, nunca se llegó a publicar).

"LAS NOTAS FANTÁSTICAS DEL CINE"

2001 El Tiempo (28 de diciembre), s.p.

Barreiro Ortiz, Juan Diego

2005 "Música en el cine colombiano", eltiempo.com (25 de junio), s.p.

Tesis de pregrado

Rosales de Gómez, Magaly

1976 El papel de la música en un medio de comunicación social: el cine. PUJ (Pontificia Universidad Javeriana), dir. de tesis Enrique de la Hoz Díaz.

Montoya Piedrahita, Mauricio

1989 Técnica y sentido del sonido en el cine argumental. UPB (Universidad Pontificia Bolivariana, sede Medellín), dir. de tesis Juan Guillermo Arredondo.

Molina Valencia, José Luis

2001a La música en el largometraje argumental colombiano entre 1990 y 1999. UPB (sede Medellín), dir. de tesis Edda Pilar Duque Isaza.

Rueda GutiérRez, Juliana

2001b Post-producción de audio para la película "La primera noche". Composición grabación y mezcla de la música para el corto "El café de mañana". PUJ, dir. de tesis Ricardo Escallón Gaviria.

Alayón Arias, Roberto Ignacio

2005a El despertar de las marionetas. PUJ, dir. de tesis Nicolás Uribe Benninghoff.

Trujillo Medina, Sergio Andrés

2005b Creación de la música para el cortometraje "Fabio Rojas". PUJ, dir. de tesis Nicolás Uribe Benninghoff.

Linares Arciniegas, María

2006 El equipo del sol. PUJ, dir. de tesis Nicolás Uribe Benninghoff.

Nieve Lozano, León ANDrés

2007 Musicalización del cortometraje "El buscapersonas". PUJ, dir. de tesis Moisés Herrera Acosta.

Olaya Maldonado, Oscar Javier

2009 Música para cine. PUJ, dir. de tesis Richard Iván Córdoba.

EsPinal Ortiz, Adriana

2010 La ingeniería de sonido en la producción de música para cine en Colombia. PUJ, dir. de tesis Ricardo Escallón Gaviria.

Obras citadas

"LA ÓPERA EN El Olympia"

1915 Olympia, serie 1a, N $^{\circ} 10$ (21 de agosto), p. 1. Bogotá: Di Domenico Hermanos \& C.a.

"LOS SEÑORES DE LA MÚSICA"

1919 Películas, año 3, N 121, s.p. 
Álvarez, Luis Alberto

1992 Páginas de cine, 3 vols. Medellín: Universidad de Antioquia.

AÑEZ, JoRGE

1968 Canciones y recuerdos, $2^{\circ}$ ed. Bogotá: Ediciones Mundial.

Atehortúa, Blas Emilio

1971 “Música de la película”, Lámpara, vol. 15, № 7, pp. 21-22.

Barreiro Ortiz, Carlos

2005 a "Música en el cine colombiano", eltiempo.com (25 de junio) (consulta: 3 de octubre de 2012), s.p.

2005b Compositores colombianos en el cine nacional. Folleto de la serie Cine años del cine. Bogotá: Centro Colombo Americano.

2006 "Luis Antonio Escobar. Un compositor para el cine colombiano", Revista Universidad de Antioquia, $\mathrm{N}^{\circ} 283$, pp. 111-113.

Bermúdez, EgBERTo

2006 "La Universidad Nacional y la investigación musical en Colombia: tres momentos". En Miradas a la Universidad Nacional de Colombia, editado por Universidad Nacional de Colombia, Dirección Nacional de Divulgación Cultural. Bogotá: Universidad Nacional de Colombia, pp. 7-83.

Caicedo González, Juan Diego

1995 “Acerca de la indisolubilidad de los vínculos entre la música y el cine”, Ensayos, vol. 2, No 2, pp. 97-132.

Camuñas, Carlos Rafael

1988 "En defensa de la música cinematográfica", Documento Cinematográfico Latinoamericano, $\mathrm{N}^{\circ} 10$, pp. 47-48.

DuQue, EdDa Pilar

1988 Veintiún centavos de cine. Medellín: Ediciones Autores Antioqueños.

1992 La aventura del cine en Medellín. Bogotá: Universidad Nacional de Colombia / El Ancora Editores.

Fundación Patrimonio Fílmico Colombiano (FPFC)

2007 Publicaciones periódicas de cine y video en Colombia 1908-2007. Bogotá: Fundación Patrimonio Fílmico Colombiano.

ca.2009 Historia del cine colombiano. Bogotá: Fundación Patrimonio Fílmico Colombiano.

Gil Araque, Fernando (Ed.)

Biblioteca digital de música. URL http:/ / www.bdmusica.eafit.edu.co/ (consulta: 4 de noviembre de 2012)

GonzÁlez Coutín, H

1924 "La tragedia del silencio", Cine Colombia, s.p.

Hoyos Pérez, Bernardo

1995 "La música y el cine”, Lámpara, vol. 33, № 127, pp. 31-35.

Igualada, Fray Francisco de

1938 "Musicología indígena de la Amazonía Colombiana", Boletín Latino-Americano de Música, Tomo IV, pp. 638-861. 
Isaza Martínez, Ignacio

1937 "El cinema y la música", Revista "Pan", N 17, pp. 10-14.

1951 Cuentos paisas. Medellín: Olympia.

1966 “Titiribí, cuna de la copla y el tipismo”, Distrito, N 8, pp. 35-37.

2014 "Cinema and Music (1937) by Ignacio Isaza Martínez", intr. y trad. Marco Alunno, Music, Sound and the Moving Image, vol. 8, $\mathrm{N}^{\circ} 1$, pp. 87-91.

Likosova, Galina y Hernán Humberto Restrepo (grupo de investigación Interdís)

2008 Blas: El hombre y su leyenda [DVD]. Medellín: Ed. Universidad Nacional de Colombia.

Lugo Febres, Martín

2006 "Reflexiones sobre las implicaciones del sonoro", Consecuencia, № 4 (ene.-mayo), pp. 46-51.

Martínez Pardo, Hernando

1978 Historia del cine colombiano. Bogotá: Ed. Guadalupe.

Miceli, Sergio

1990a "Storiografia musicale italiana e musica del cinema". En Sergio Miceli (ed.), Atti del Convegno Internazionale di Studi Musica E̋ Cinema (Siena, 19-22 agosto 1990), núm. esp. de Chigiana, vol. 42, No 22. Florencia: Olschki, pp. 201-222.

1990b "La manualistica storico-musicale fra tentazioni divulgative e imbarazzo accademico", beQuadro, vol. 19, Nos. 73-74, pp. 7-13.

Montoya, Juan David

2012 "Medellín podría ser Meca del cine", El Colombiano online (15 de junio). URL http://www.elcolombiano.com/BancoConocimiento/M/medellin_podria_ ser_meca_del_cine/medellin_podria_ser_meca_del_cine.asp (consulta: 4 de noviembre de 2012)

Nieto, Jorge y Diego Rojas

1992 Tiempos del Olympia. Bogotá: Banco de Colombia.

PARdo TOVAR, ANDrÉs

1966 La cultura musical en Colombia: Historia extensa de Colombia. Bogotá: Academia Colombiana de Historia.

Perdomo Escobar, José Ignacio

1945 Historia de la música en Colombia. Bogotá: Ministerio de Educación Nacional.

Salcedo Silva, Hernando

1981 Crónicas del cine colombiano, 1897-1950. Bogotá: Carlos Valencia Editores.

SuÁrez, JuANA

2009 Cinembargo Colombia: ensayos críticos sobre cine y cultura. Cali: Universidad del Valle.

VALVERDE, UMBERTO

1978 Reportaje crítico al cine colombiano. Bogotá-Cali: Editorial Toronuevo.

Velásquez Ospina, Juan Fernando

2012 Los ecos de la villa. Medellín: Alcaldía de Medellín.

Zapata Cuencar, Heriberto

1962 Compositores colombianos. Medellín: Editorial Carpel. 
Zulategui, Luis Miguel de

1943 "Fantasía”, Micro, No 52, pp. 11 y 44.

Zuluaga, Pedro Adrían

2007 ¡Acción! Cine en Colombia. Bogotá: Museo Nacional de Colombia.

Bibliografía adicional consultada sobre el cine y la crítica de cine en Colombia

Álvarez, Carlos

1989 Sobre cine colombiano y latinoamericano. Bogotá: Universidad Nacional de Colombia.

Arbelaez Ramos, Ramiro y Juan Gustavo Cobo Borda

2011 La crítica de cine, una historia en texto: artículos memorables en Colombia 1897-2000. Bogotá: Universidad Nacional de Colombia, Proimagenes Colombia.

Avila Gómez, Jairo Andrés y Fabio López SuÁrez

2006 Salas de cine. Bogotá: Secretaría General, Alcaldía Mayor.

Ramos Garbiras, Alberto

1982 Textos de cine 1977-1982. Cali: Imprenta Departamental, SEC. 